\title{
Prevalence of toxoplasma myocarditis in patients with the acquired immunodeficiency syndrome
}

\author{
Paul Hofman, Milou-Daniel Drici, Pierre Gibelin, Jean-François Michiels, Antoine Thyss
}

\begin{abstract}
Objective-To evaluate the prevalence of cardiac toxoplasmosis in a series of 182 necropsies performed between 1987 and 1991 on patients infected with the human immunodeficiency virus (HIV), to correlate this prevalence with the ante mortem diagnosis of cardiac involvement, and to assess the role of such cardiac lesions in the immediate cause of death.

Patients and methods-Complete necropsies of 182 HIV-infected patients (48 women, 134 men) were performed consecutively between 1987 and 1991. Risk factors, identified in 174 cases, included drug abuse (111/182), homosexuality (51/182), and blood transfusions (12/182). 16 samples were systematically obtained from each heart for histological study. If trophozoites or lymphocytic myocarditis were seen, immunohistochemical investigations were carried out with polyclonal antibodies for Toxoplasma gondii. An ultrastructural study was performed in four patients with toxoplasma myocarditis. Myocardial lesions were defined by the Dallas classification. Clinical data (and information on electrocardiograms and echocardiograms) were obtained from medical records.
\end{abstract}

Results-Cardiac toxoplasmosis was diagnosed at necropsy in 21 (12\%) patients. Cardiac lesions were associated with toxoplasmic encephalitis in 18 patients and were solitary in three patients. Acute diffuse myocarditis was present in $6 / 21$, rare foci of myocarditis were seen in 8/21, and intramyocytic toxoplasmic cysts without any inflammatory reaction or necrosis were seen in 4/21. Anti-toxoplasma immunolabelling showed cardiac toxoplasmosis in three patients with lymphocytic myocarditis. Particles with the ultrastructural characteristics of Toxoplasma gondii trophozoites were seen in four cases. Six patients had presented with cardiac symptoms, confirmed by electrocardiographic and echocardiographic abnormalities during their disease course, and their cardiac lesions were directly responsible for the death.

Conclusion-Cardiac toxoplasmosis was common in this necropsy series of HIVinfected patients. Cardiac toxoplasmosis had been suspected clinically in four patients. Myocardial lesions were gener- ally asymptomatic and were not discovered until necropsy. Solitary cardiac involvement was not uncommon reflecting parasite reactivation at a myocardial site. The incidence of cardiac toxoplasmosis in this group of immunodepressed subjects from an area with a high prevalence of this parasitic disease justifies regular follow up of such patients by electrocardiography and echocardiography as well as immediate administration of anti-toxoplasma treatment should sudden heart failure occur.

(Br Heart f 1993;70:376-381)

The cardiac lesions seen in patients with the acquired immune deficiency syndrome (AIDS) are dominated by lymphocytic myocarditis, ${ }^{12}$ which usually has a viral ${ }^{3-5}$ or toxic cause agent. ${ }^{6-8}$ Toxoplasmic myocarditis, though less common, has been reported in several necropsy series. ${ }^{9-11}$ The exact incidence and significance of cardiac involvement by Toxoplasma gondii are difficult to establish in patients infected by HIV. Rare cases of toxoplasma myocarditis responsible for heart failure of sudden onset ${ }^{12}$ or sudden death ${ }^{13}$ have been described. Often asymptomatic, these cardiac lesions can be masked by neurological symptoms. ${ }^{9}$ In the absence of systematic anatomical verification, their incidence is probably underestimated in AIDS.

Cardiac toxoplasmosis generally occurs during the course of multivisceral dissemination, but isolated lesions have been seen without cerebral involvement ${ }^{91314}$ reflecting reactivation of Toxoplasma gondii parasites as a consequence of immunodepression. Reactivation occurs in the cardiomyocytes, one of the usual sites of parasite encystment after primary toxoplasmic infection.

Cardiac toxoplasmosis can be treated effectively by a combination of sulphadiazine and pyrimethamine, ${ }^{12}$ if the disease is diagnosed before extensive, irreversible myocardiac lesions develop. Though diagnosis is exceptionally made by examination of endomyocardial biopsy material, 1516 epidemiological, clinical, and paraclinical data are the usual means of diagnosis.

This study was designed to evaluate retrospectively the prevalence of cardiac toxoplasmosis in a necropsy series of 182 patients who died of AIDS. Results were compared with the diagnosis made on the basis of clinical data. 
Patients and methods

Consecutive systematic necropsies of 182 patients (48 women, 134 men) who died of AIDS, as defined by the Atlanta Center for Disease Control, ${ }^{17}$ were performed between March 1987 and December 1991 at the Nice University Medical Centre. One hundred and eleven of the patients had been intravenous drug abusers, 51 were homosexuals, and 12 had received multiple blood transfusions. No risk factors could be identified for the remaining eight patients. Gross examination of the heart was performed on fresh, unfixed specimens at necropsy. The heart was weighed and the coronary arteries were dissected immediately. The thickness of the left ventricle was measured at the inferior edge of the anterior valve. For histological study, 16 samples were taken systematically after $48 \mathrm{~h}$ fixation in $10 \%$ buffered formalin solution: six from the left ventricle, three from the right ventricle, three from the interventricular septum, two from the coronary network and two from the parietal pericardium All sections were stained with haematoxylin and eosin. Whenever an inflammatory infiltrate was present, sections were also analysed with Giemsa, Gomori-Grocott, and periodic acidSchiff (PAS) stains. Immunohistochemical study with polyclonal Toxoplasma gondii anti- bodies (ICN Biomedicals, Costa Mesa USA) was performed when trophozoites or lymphocytic myocarditis were present. Toxoplasmic encephalitis lesions served as positive controls.

Specimens from four patients with myocardial microabscesses were fixed in $2.5 \%$ diluted glutaraldehyde for ultrastructural study with a JEOL 1200 EXII transmission electron microscope. Myocarditis was defined according to the Dallas criteria as "a process characterized by an inflammatory infiltrate of the myocardium with necrosis and degeneration of adjacent myocytes not typical of the ischemic damage associated with coronary artery disease". ${ }^{18}$

Clinical data and information on the electrocardiogram, the echocardiogram, computed tomographic brain scans, serological diagnosis of toxoplasma, and number of positive CD4 lymphocytes were obtained from the medical files. The immediate cause of death was determined by comparing the clinical history and necropsy findings.

\section{Results}

PATIENT CHARACTERISTICS

Twenty one $(12 \%)$ of the 182 patients had cardiac toxoplasmosis. Tables 1 and 2 summarise the epidemiological and clinical data.

Table 1 Epidemiological and clinical data on patients without cardiac manifestations

\begin{tabular}{|c|c|c|c|c|}
\hline Patient & Sexlage/risk & $\begin{array}{l}\text { General clinical } \\
\text { features }\end{array}$ & $\begin{array}{l}\text { Antitoxoplasmosis } \\
\text { treatment }\end{array}$ & $\begin{array}{l}\text { Cardiac histological } \\
\text { findings }\end{array}$ \\
\hline 1 & F/34/IVDU & $\begin{array}{l}\text { Toxoplasmosis (CTS) } \\
\text { Cytomegalovirus }\end{array}$ & + & Lymphocytic myocarditis \\
\hline 2 & F/36/IVDU & $\begin{array}{l}\text { Toxoplasmosis (CTS) } \\
\text { Mycobacterium tuberculosis }\end{array}$ & + & Isolated Toxoplasma cysts \\
\hline 3 & $\mathrm{~F} / 29 / \mathrm{PT}$ & $\begin{array}{l}\text { Toxoplasmosis (CTS) } \\
\text { Cytomegalovirus }\end{array}$ & + & Isolated Toxoplasma cysts \\
\hline $\begin{array}{l}4 \\
5 \\
6\end{array}$ & $\begin{array}{l}\text { F/27/IVDU } \\
\text { F/27/IVDU } \\
\text { F/31/IVDU }\end{array}$ & $\begin{array}{l}\text { Candidiasis } \\
\text { Cryptococcosis } \\
\text { Toxoplasmosis (CTS/BAL) } \\
\text { Pneumocystis }\end{array}$ & $\begin{array}{l}- \\
+ \\
+\end{array}$ & $\begin{array}{l}\text { Lymphocytic myocarditis } \\
\text { Toxoplasma myocarditis } \\
\text { Toxoplasma myocarditis }\end{array}$ \\
\hline $\begin{array}{l}7 \\
8 \\
9\end{array}$ & $\begin{array}{l}\text { M/42/IVDU } \\
\text { M/39/IVDU } \\
\text { M/25/HS }\end{array}$ & $\begin{array}{l}\text { Cytomegalovirus } \\
\text { Toxoplasmosis (CTS) } \\
\text { Toxoplasmosis (CTS) } \\
\text { Candidiasis }\end{array}$ & $\begin{array}{l}- \\
+ \\
+\end{array}$ & $\begin{array}{l}\text { Toxoplasma myocarditis } \\
\text { Isolated Toxoplasma cysts } \\
\text { Toxoplasma myocarditis }\end{array}$ \\
\hline $\begin{array}{l}10 \\
11\end{array}$ & $\begin{array}{l}\text { M/28/HS } \\
\text { M/30/IVDU }\end{array}$ & $\begin{array}{l}\text { Immunoblastic lymphoma } \\
\text { Toxoplasmosis (CTS) } \\
\text { Pneumocystis }\end{array}$ & $\overline{+}$ & $\begin{array}{l}\text { Toxoplasma myocarditis } \\
\text { Lymphocytic myocarditis }\end{array}$ \\
\hline 12 & $\mathrm{M} / 34 / \mathrm{HS}$ & $\begin{array}{l}\text { Toxoplasmosis (CTS) } \\
\text { Pneumocystis }\end{array}$ & + & Toxoplasma myocarditis \\
\hline 13 & $\mathrm{M} / 38 / \mathrm{HS}$ & $\begin{array}{l}\text { Toxoplasmosis (CTS) } \\
\text { Cytomegalovirus }\end{array}$ & + & Toxoplasma myocarditis \\
\hline $\begin{array}{l}14 \\
15\end{array}$ & $\begin{array}{l}\mathrm{M} / 41 / \mathrm{HS} \\
\mathrm{M} / 32 / \mathrm{HS}\end{array}$ & $\begin{array}{l}\text { Toxoplasmosis (CTS) } \\
\text { Toxoplasmosis (CTS) } \\
\text { Cytomegalovirus }\end{array}$ & $\begin{array}{l}+ \\
+\end{array}$ & $\begin{array}{l}\text { Toxoplasma myocarditis } \\
\text { Isolated Toxoplasma cysts }\end{array}$ \\
\hline
\end{tabular}

IVDU, intravenous drug user; HS, homosexual; PT, post-transfusion; BAL, bronchoalveolar lavage; CTS, computed tomographic brain scan.

Table 2 Cardiac findings in six AIDS patients with diffuse toxoplasma myocarditis

\begin{tabular}{lllllll}
\hline Patient & Sex/age/risk & $\begin{array}{l}\text { General clinical } \\
\text { features }\end{array}$ & $\begin{array}{l}\text { Antitoxoplasmosis } \\
\text { treatment }\end{array}$ & $E F$ & $\begin{array}{l}\text { LVIDd } \\
(\mathrm{cm})\end{array}$ & $E C G$ \\
\hline 16 & F/34/IVDU & Pneumocystosis & - & $0 ; 38$ & $5 \cdot 45$ & $\begin{array}{l}\text { ST and T wave } \\
\text { abnormalities }\end{array}$ \\
17 & F/29/IVDU & $\begin{array}{l}\text { Pneumocystosis } \\
\text { candidiasis }\end{array}$ & - & $0 ; 35$ & $5 \cdot 90$ & $\begin{array}{l}\text { T Wave } \\
\text { abnormalities }\end{array}$ \\
18 & M/52/IVDU & $\begin{array}{l}\text { Toxoplasmosis (CTS), } \\
\text { aspergillosis }\end{array}$ & Arrest & $0 ; 32$ & $6 \cdot 10$ & LBBB \\
19 & Maposi sarcoma, & Arrest & $0 ; 37$ & $5 \cdot 90$ & Low voltage \\
20 & M/29/HS & $\begin{array}{l}\text { Pneumocystosis } \\
\text { candidiasis toxoplasmosis (CTS) } \\
\text { Kaposi sarcoma toxoplasmosis (CTS/BAL) }\end{array}$ & Arrest & ND & ND & T wave \\
21 & M/38/HS & Arrest & $0 ; 30$ & $6 \cdot 21$ & $\begin{array}{l}\text { ST and T wave } \\
\text { abnormalities }\end{array}$ \\
\hline
\end{tabular}

IVDU, intravenous drug user; HS, homosexual; CTS, computed tomographic brain scan; PT, post-transfusion; BAL, IVDU, intravenous drug user; HS, homosexual; CTS, computed tomographic brain scan; PT, post-transfusion; BAL,
bronchoalveolar lavage; EF, left ventricular ejection fraction by echocardiography; LVIDd, left ventricular internal diameter at bronchoalveolar lavage; EF, left ventricular ejection fraction by echocardiography;
diastole by echocardiography; LBBB, left bundle branch block; ND, not performed. 
All patients were white. Their mean age was 34 years (range 23-63). All had developed at least one opportunist infection during their disease course. The mean duration of the disease course from diagnosis of AIDS until death was 24 months (range 2-29) The mean number of positive CD4 $\mathrm{T}$ lymphocytes at the time of death was $15 / \mathrm{mm}^{3}$ (range $0-40 / \mathrm{mm}^{3}$ ).

All 21 patients for a mean of 14 months (range 1-32) were treated with zidovudine. Nineteen patients were febrile and had several peaks of high fever $\left(40^{\circ} \mathrm{C}\right)$ in the month preceding death. Serological tests showed a stable and only slightly raised anti-toxoplasmosis IgG titre in 16 cases, and a considerable increase in IgG without IgM in the other five patients. Computed tomographic images suggestive of cerebral toxoplasmosis were seen in 15: these patients were treated with pyrimethamine and sulphadiazine but five of them died rapidly. In four other patients, treatment had been interrupted at the time of death because of haematological toxicity. Six patients had electrocardiographic and echocardiographic evidence of heart disease (table 2): cardiac involvement was the direct cause of death in all six. The other causes of death included lesions of the central nervous system (12), pulmonary failure (two), and gastrointestinal bleeding (one).

\section{PATHOLOGICAL CARDIAC FINDINGS}

The mean (1SD) heart weight was 385 (51) g but it was significantly lower in four cachectic patients $(<210 \mathrm{~g})$. Moderate or extensive pericardial effusion $(>150 \mathrm{~g})$ was noted in four. Left ventricular myocardial hypertrophy $(>2 \mathrm{~cm})$ was seen in four, and three hearts showed biventricular dilatation. Disseminated microabscesses were found in four.
HISTOLOGICAL FINDINGS

Cardiac toxoplasmosis was seen in 21 patients. Solitary lesions were found in the myocardium of three and were responsible for sudden death in two of them. The remaining 18 patients also had toxoplasmic encephalitis. In 11 cases toxoplasma had disseminated to the lungs (10), pancreas (two), and testicles (two). The extensive myocardial lesions noted in six included a large area of myocytic necrosis, oedema, a polymorphonuclear inflammatory infiltrate, a few true cysts (fig 1), and numerous intracellular pseudocysts composed of clumps of trophozoites (fig 2). Mild focal myocarditis with trophozoites was seen in eight patients. Four patients had isolated toxoplasmic cysts in myocytes, without any inflammatory reaction. The intracellular toxoplasmic cysts were $50-200 \mu \mathrm{m}$ in diameter and their wall was stained by Gomori-Grocott. The trophozoites were stained by Giemsa and PAS. Lymphocytic myocarditis without any identifiable pathogen was seen in 15 of the 182 patients. These focal lesions (4-15 per heart) consisted of necrotic myocytes with perivascular and interstitial lymphocytic infiltrates and were especially prevalent in the left ventricle.

\section{IMMUNOHISTOCHEMICAL AND ELECTRON} MICROSCOPY STUDY

Immunohistochemistry with antibodies to Toxoplasma gondii confirmed the presence of toxoplasmic cysts and pseudocysts and demonstrated free trophozoites within necrotic zones. Three cases of lymphocytic myocarditis studied by immunohistochemical toxoplasmic antibodies were positive (fig 2 (inset)). Ultrastructural study of four patients confirmed the presence of Toxoplasma gondii trophozoites in the cytoplasm of cardiac
Figure 1 Histological section of myocardium showing an intramyocytic toxoplasma cyst (arrow) (haematoxylin eosin; original magnification $\times 320$ ).

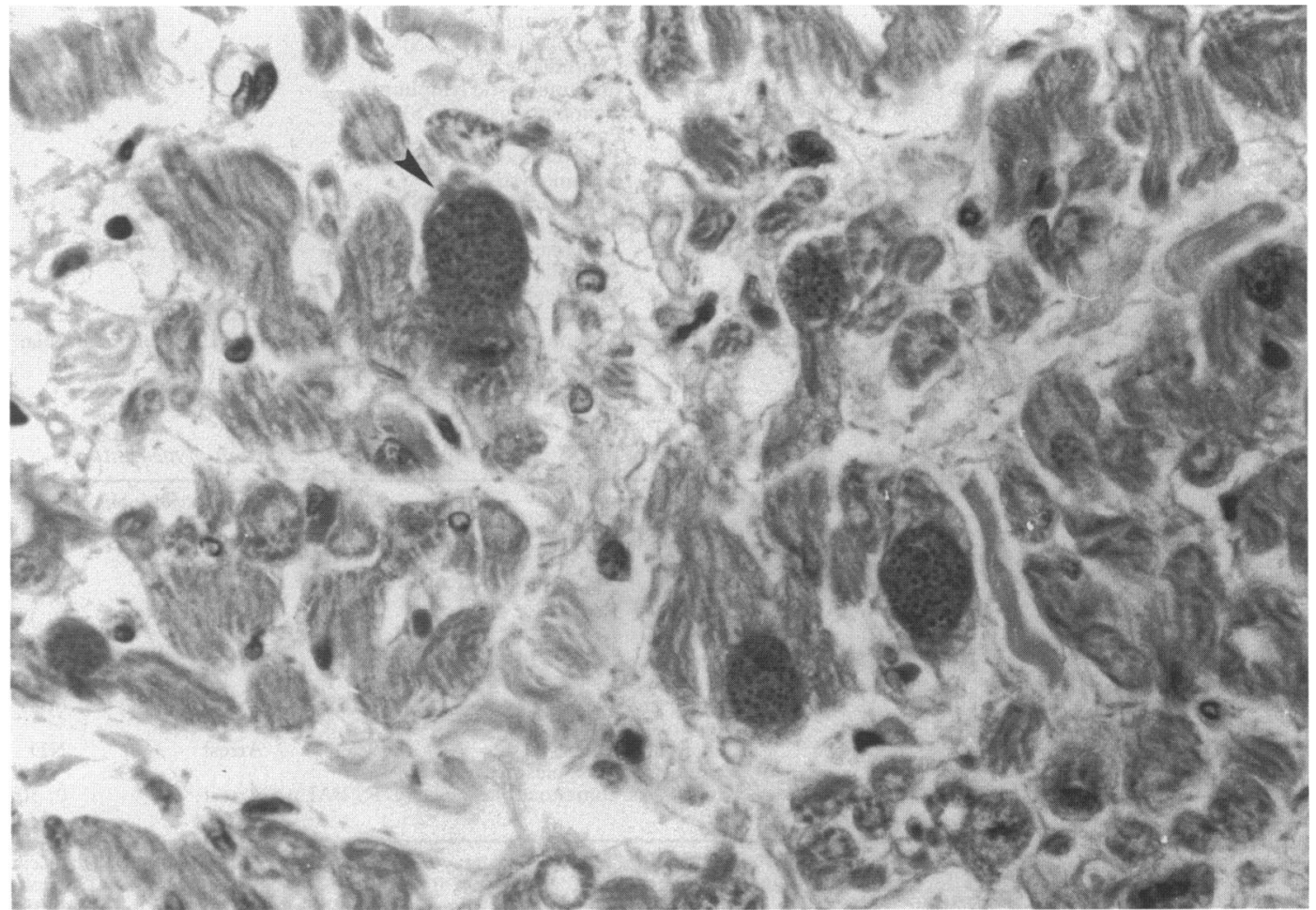


Figure 2 Histological section of myocardium showing diffuse toxoplasma myocarditis with cellular necrosis and an inflammatory cell infiltrate. The arrow indicates pseudocysts in a cardiac cell haematoxylin eosin; original

magnification, $\times 320$ ).

The inset shows free

trophozoites (anti-

toxoplasma

immunolabelling; original magnification, $\times 800$

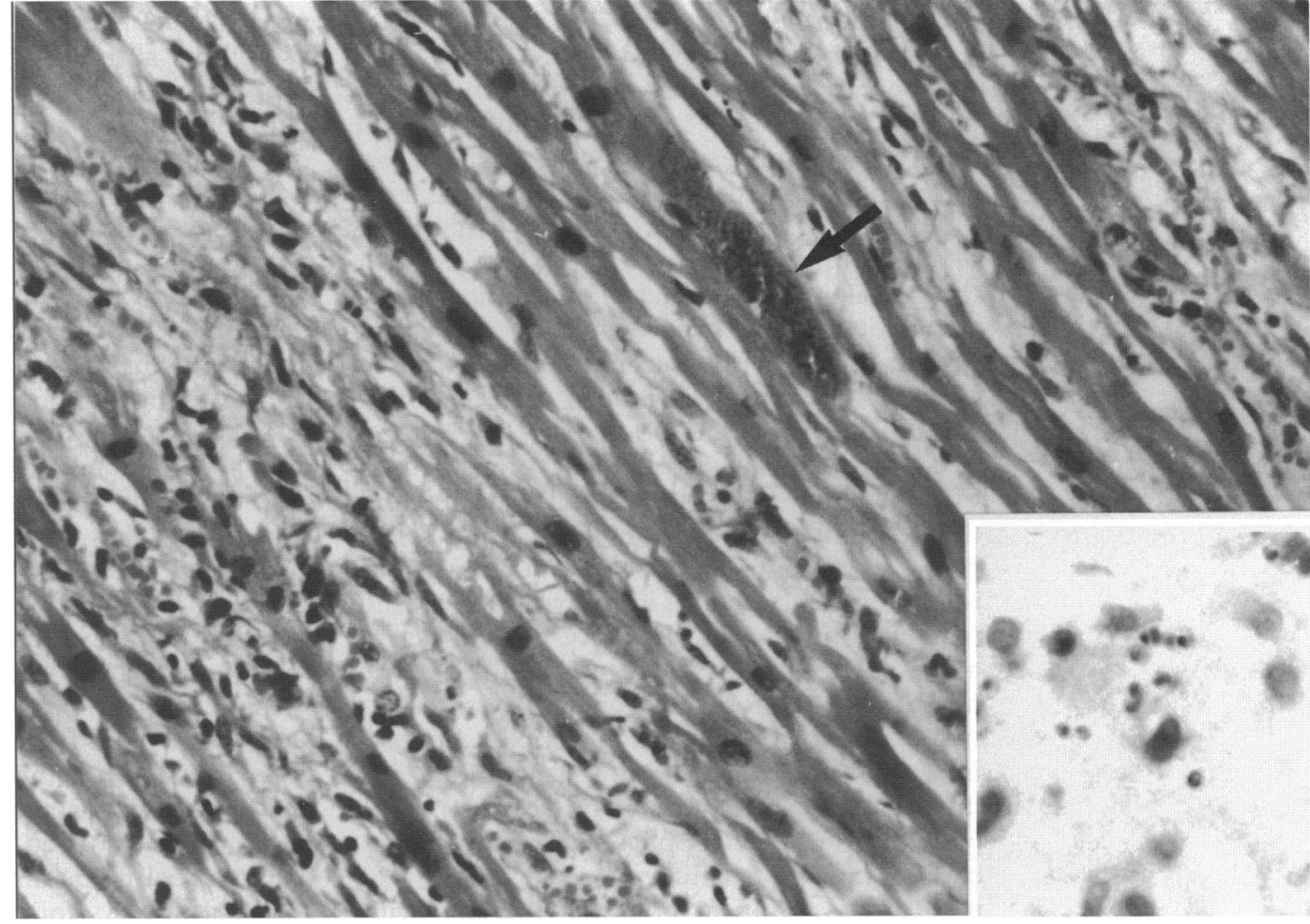

muscle cells or free within the interstitium. Tachyzoites were seen in parasitophore vacuoles within cardiomyocytes (fig 3). These parasites were delimited by a double membrane, contained 4-5 rhoptries, and their tip had a honeycomb structure

MAIN NECROPSY FINDINGS Twenty of the 21 patients had central had multivisceral Kaposi's sarcoma. nervous system involvement: toxoplasma encephalitis (18), progressive multifocal leucoencephalopathy (one), cytomegalovirus encephalitis (one). Eighteen of the 21 patients had pulmonary involvement: toxoplasmosis (10), pneumocystis (five), cytomegalovirus pneumonia (two), invasive candidiasis (one). Two patients had disseminated malignant lymphoma while two others
Figure 3 Electron micrograph showing Toxoplasma gondii trophozoites in a cardiomyocyte (original magnification $\times 6200$ ).

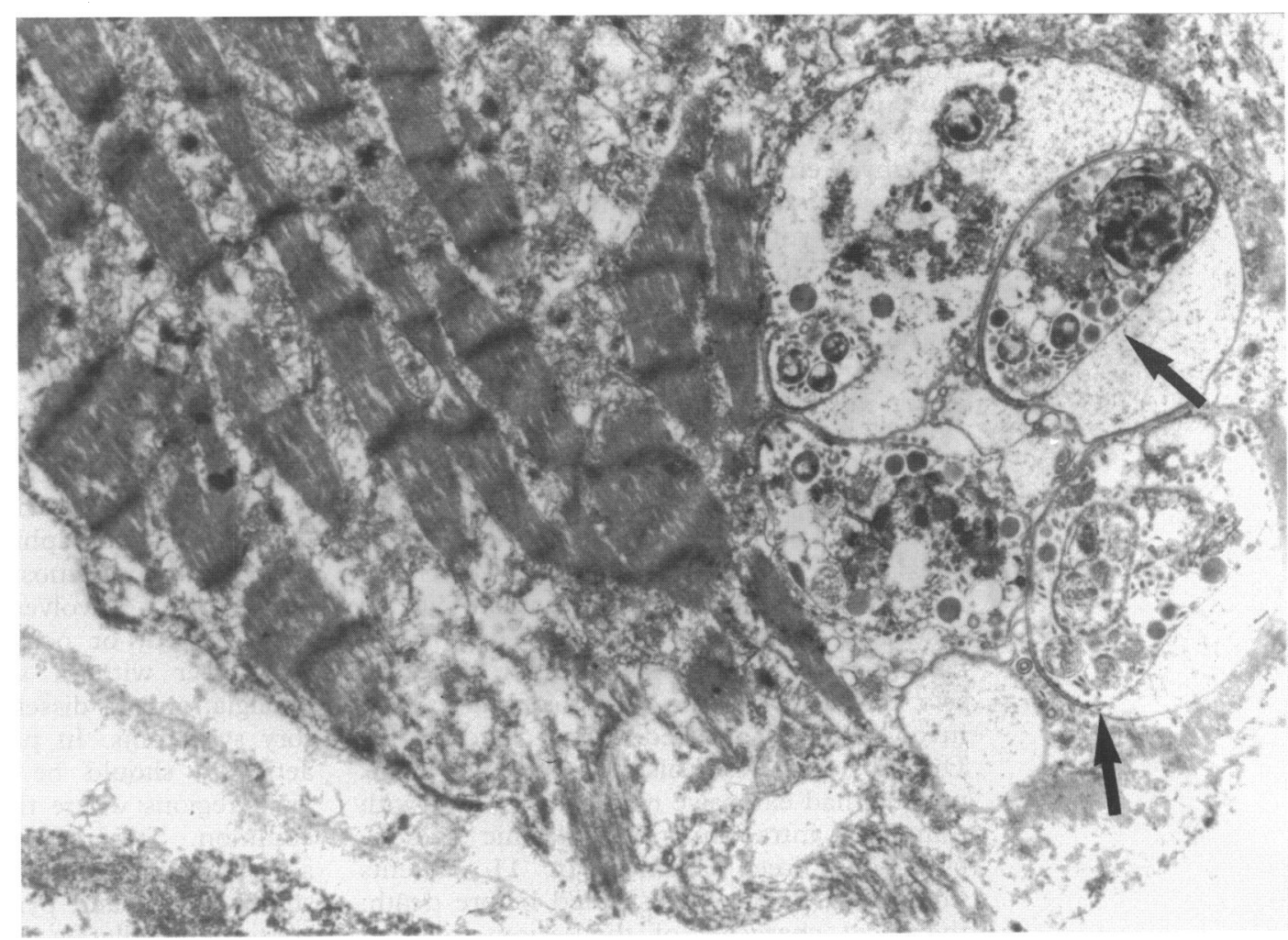




\section{Discussion}

Cardiac toxoplasmosis was more common in our necropsy series than in most other comparable studies. ${ }^{1014}$ Only Roldan et al reported an incidence of $14 \%$ in a necropsy series in which most of the patients were from Haiti. ${ }^{9}$ The frequency of lesions attributable to Toxoplasma gondii correlated closely with the prevalence of toxoplasmosis in the general population. This prevalence is markedly higher in southern Europe (up to $85 \%$ in France) and in the Caribbean than in northern Europe or the United States. ${ }^{19}$

The intensity of myocardial lesions caused by Toxoplasma gondii varied considerably, and the different manifestations seen in our series could represent various stages of the disease related to the degree of intramyocytic parasite reactivation. Lesion severity varied from acute diffuse myocarditis involving the entire heart muscle to foci of toxoplasmic myocarditis localised in the left ventricle. Solitary intramyocytic toxoplasma cysts without any inflammatory reaction were seen in four patients, but strict application of the Dallas classification $^{18}$ precluded a diagnosis of myocarditis. Anti-toxoplasma therapy with sulphadiazine and pyrimethamine is effective on pseudocysts and free trophozoites but has no effect on encysted forms, which persist within cardiomyocytes. Interruption of treatment triggers reactivation of the parasite that is and leads to progressive disease. For example, acute diffuse toxoplasmic myocarditis was seen in four patients whose anti-toxoplasma treatment had been interrupted because of haematological toxicity. The importance of solitary cysts could not be determined. They could be rare entities also seen in healthy subjects in the absence of toxoplasmic disease or early signs of trophozoite reactivation in muscle cells just before cysts rupture. Latent parasitic infection controlled by anti-toxoplasma treatment is a more likely explanation. In our three patients cardiac lesions alone without associated cerebral involvement probably reflect toxoplasma reactivation of a latent intramyocytic infection. The multi-organ toxoplasma involvement seen in the other patients raises the possibility of primary toxoplasmic infection during the period of immunodepression linked to HIV. Simultaneous parasitic reactivation in several organs is another possibility.

Myocarditis was suspected on the basis of clinical findings in six patients (table 1 ) with fever $\left(40^{\circ} \mathrm{C}\right)$, global heart failure of sudden onset, and biventricular hypokinesia. The coexistence of computed tomographic brain scans suggestive of toxoplasmosis indicated that Toxoplasma was responsible for myocarditis in four of the six cases. In the other two cases, the solitary nature of the cardiac involvement suggested viral myocarditis. During postmortem histological study all six patients had extensive myocytic necrosis with numerous intracellular toxoplasmic pseudocysts and free parasites. In 11 patients myocarditis was not suspected before death: the focal character of the lesions seen at necropsy could explain the absence of cardiac symptoms and lack of effects on myocardial function. The four patients with isolated solitary toxoplasma cardiac cysts did not have cardiac symptoms.

The frequency of cardiac toxoplasmosis in our study indicates the value of endomyocardial biopsies in AIDS patients. Such biopsies are justified in HIV-infected patients who develop heart failure of rapid onset with accompanying fever. However, Grange et al drew attention to the possibility of false negative errors owing to the heterogeneous nature of myocardial involvement in toxoplasmosis and the small size of the biopsy samples. ${ }^{12}$ When an inflammatory infiltrate without any visible parasites is found, the differential diagnosis between viral or toxic myocarditis is difficult. Systematic anti-toxoplasma immunolabelling is necessary for all biopsy specimens. In our series, this examination was positive in three cases of lymphocytic myocarditis, even though the parasites were not visible with standard stains. Toxoplasma gondii can be isolated by inoculation of tissue or biological fluids into laboratory animals or cell cultures, ${ }^{20}$ and whenever toxoplasma myocarditis is suspected a cardiac biopsy should be performed for such studies. The role of gene amplification techniques with polymerase chain reaction on myocardial biopsy specimens remains to be established for the diagnosis of toxoplasma myocarditis. ${ }^{21}$ This method, which is hard to apply routinely, has the drawback of detecting intracellular parasites in a latent state in patients without progressive toxoplasmosis.

In France, the decline in certain opportunist infections (pneumocytosis, candidiasis) and Kaposi's sarcoma could explain the increased incidence of toxoplasmosis since 1986.22 Toxoplasma gondii often causes lesions in the central nervous system but the prevalence of cardiac toxoplasmosis in our study highlights the frequency of extracerebral involvement. The functional consequences of toxoplasmosis infection in the myocardium vary considerably, depending on the intensity of the inflammatory reaction and the extent of parasitic reactivation. Toxoplasmic myocarditis can cause sudden death or have no impact on myocardial function. In the absence of reliable techniques for the serological diagnosis of toxoplasma in immunodepressed AIDS patients, ${ }^{20}$ several findings suggest a diagnosis of toxoplasmic myocarditis in patients with heart failure. These are computed tomographic brain scans compatible with toxoplasmosis (though central nervous system involvement may be absent, undiagnosed, or occur secondarily); persistent fever without any isolated pathogen; myalgia; and in disseminated forms, respiratory symptoms. In particular, a toxoplasma aetiology should be suspected in patients from regions where the parasite is especially common. Systematic echocardiograms are advisable in such cases, and treatment by sulphadiazine and pyrimethamine should be started immediately. Finally, when endomyo- 
cardial biopsy specimens are available, antitoxoplasmic immunohistochemical study and inoculation of tissue into animals or cell cultures should improve the sensitivity of histological diagnosis.

1 Acierno LJ. Cardiac complications in acquired immunodeficiency syndrome (AIDS) a review. $\mathcal{F} \mathrm{Am}$ Coll Cardiol 1989;13:1144-54.

2 Baroldi G, Corallo S, Moroni M, Repossini A, Mutinelli MR, Lazzarin A, et al. Focal lymphocytic myocarditis in the acquired immunodeficiency syndrome. A correlative morphologic and clinical study in 26 consecutive fatal cases. F Am Coll Cardiol 1988;12:463-9.

3 Beschorner WE, Baughman K, Turnicky RP, Hutchins GB, Rowe SA, Kavanaugh MC, et al. HIV associated myocarditis. Pathology and immunopathology. Am $\mathcal{f}$ Pathol 1990;137:1365-71.

4 Dittrich H, Chow L Denaro F. Human immunodeficiency virus, coxsackie virus and cardiomyopathy. Ann ciency virus, coxsackie virus

5 Grody WW, Cheng L, Lewis W. Infection of the heart by the human immunodeficiency virus. Am $\mathcal{F}$ Cardiol 1990 66:203-6.

6 Turnicky RP, Goodin J, Smialek JE, Herskowitz A, Beschorner WE. Incidental myocarditis with intravenous drug abuse. The pathology, immunopathology and potential implications for human immunodeficiency
virus associated myocarditis. Hum Pathol 1992;23: 138-43.

7 Herskowitz A, Willoughby SB, Baughman KL, Schuilman SP, Bartlett JD. Cardiomyopathy associated with antiretroviral therapy in patients with HIV infection: A report of six cases. Ann Intern Med 1992;116:311-2.

8 Peng SK, French WJ, Pelikan PCD. Direct cocaine cardiotoxicity demonstrated by endomyocardial biopsy. Arch Pathol Lab Med 1989;113:842-5.

9 Roldan EO, Moskowitz L, Hensley GT. Pathology of the heart in acquired immunodeficiency syndrome. Arch
Pathol Lab Med 1987;111:943-6.

10 Klatt EC. Diagnostic findings in patients with acquired immunodeficiency syndrome (AIDS). 7 Acquir Immune Defic Syndr 1988;1:454-65.

11 Moskowitz LB, Hensley GT, Chan JC, Adams K. Immediate cause of death in acquired immunodeficiency syndrome. Arch Pathol Lab Med 1985;109:734-8.

12 Grange F, Kinney EL, Monsuez JJ, Rybojad M, Derouin F, Khuong MA, et al. Successful therapy for Toxoplasma F, Khuong MA, et al. Successful therapy for Toxoplasma gondii myocarditis in acquired imm

13 Vynn Adair O, Randive N, Krasnow N. Isolated Toxoplasma myocarditis in acquired immunodeficiency syndrome. Am Heart f 1989;118:856-7.

14 Tschirhardt D., Klatt EC. Disseminated Toxoplasmosis in the acquired immunodeficiency syndrome. Arch Pathol Lab Med 1988;112:1237-41.

15 Luft BJ, Brooks RG, Conley FK, Cabe RE, Remington JS. Endomyocardial biopsy in the diagnosis of toxoplasmic myocarditis. Transplant Proc 1986;18:871-3.

16 Wreghitt TG, Hakim M, Gray JJ, Balfour AH, Stovin PGI, Stewart S, et al. Toxoplasmosis in heart and heart lung transplant recipients. F Clin Pathol 1989;42:194-9.

17 Center for Diseases Control. Reunion of CDC case definition for acquired immunodeficiency syndrome. definition for acquired immunod

18 Aretz HT, Billingham ME, Edmards WD. Myocarditis: a histo-pathologic definition and classification. $A m \quad \mathcal{F}$ Cardiovasc Pathol 1987;1:3-13.

19 Gentilini M, Duflo B (eds). La toxoplasmose. In: Médecine tropicale, Paris: Flammarion Médecine Science, 1986:134-40.

20 Derouin F, Sarfati C, Beauvais B, Iliou MC, Dehen L, Lariviere M. Laboratory diagnosis of pulmonary toxoplasmosis in patients with acquired immunodeficiency syndrome. F Clin Microbiol 1989;27:1661-3.

21 Weiss LM, Chen YY, Berry GJ, Strickler JG, Dorfman RF, Warnkera RA. Infrequent detection of Toxoplasma gondii genome in toxoplasmic lymphadenitis. A polygondii genome in toxoplasmic lymphadenitis. A poly-
merase chain reaction study. Hum Pathol 1992;23: 154-8.

22 Anonymous. Surveillance du SIDA en France (situation au 30 juin 1992) Bulletin Epidemiologique Hebdomadaine 1992;31:145-9. 